\title{
Single-stage transthoracic approach for right lung and liver hydatid disease
}

\author{
Ekber Şahin, MD \\ Serkan Enön, MD \\ Ayten Kayı Cangır, MD \\ Hakan Kutlay, MD \\ Şevket Kavukçu, MD \\ Hadi Akay, MD \\ İlker Ökten, MD \\ Şinasi Yavuzer, MD
}

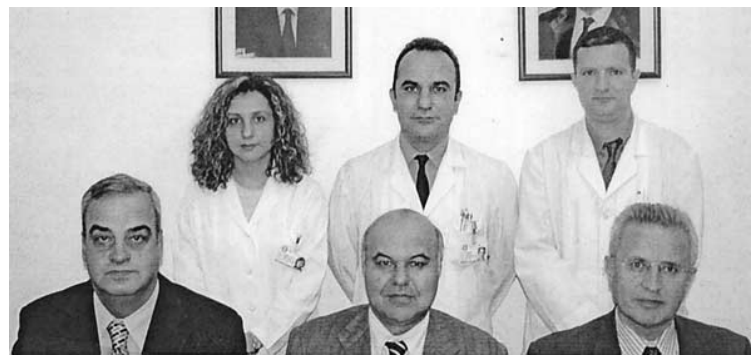

Front: Hadi Akay, İker Ökten, Şevket Kavukçu, Back: Ayten Kayı Cangır, Hakan Kutlay, Serkan Enön
Objective: Human echinococcosis remains a serious health problem for the Mediterranean countries. Synchronous pulmonary and hepatic hydatid disease may occur in $4 \%$ to $25 \%$ of cases. Our experience on simultaneous surgical treatment of right lung and liver hydatid disease in patients was reviewed.

Methods: Between 1990 and 2000, 48 patients (33 female patients and 15 male patients) with synchronous right lung and liver dome hydatid cysts were operated with a 1-stage procedure.

Results: Six patients had previous surgical treatment of hepatic $(\mathrm{n}=$ $2)$ or pulmonary $(n=4)$ hydatid cyst. The pulmonary cysts were diagnosed with radiography in 18 patients and thoracic computed tomography scan in 30. The pulmonary cysts of 9 patients were bilateral. Seventy-five pulmonary cysts were seen in radiological examinations. The diagnosis of hepatic cysts was established with ultrasonography in 18 patients and upper abdominal computed tomography in 30 . The total number of hepatic cysts was 48. In cases with pulmonary cysts, cystotomy and capitonnage were performed in 32 patients, only cystotomy was done in 14 patients, and wedge resection was performed in 2. Liver cysts were approached to transdiaphragmatically after the lung cysts had been dealt with and were managed with evacuation of the cysts. In the remaining cases, marsupialization $(n=2)$, pericystectomy $(n=1)$, and enucleation $(\mathrm{n}=1)$ were performed. Major postoperative complications were hemorrhage $(\mathrm{n}=$ 1) and biliocutaneous fistula $(\mathrm{n}=1)$. Hepatic recurrence was seen in 3 patients $(6.2 \%)$ and pulmonary recurrence in $1(2.1 \%)$.

From the Department of Thoracic Surgery, Ankara University Medical School, Ankara, Turkey.

Received for publication June 14, 2002; revisions requested Aug 26, 2002; revisions received Oct 4, 2002; accepted for publication Oct 18, 2002.

Address for reprints: Dr Şevket Kavukçu, Ankara Üniversitesi Tip Fakültesi, İbn-i Sina Hastanesi, Göğüs Cerrahisi Anabilim Dalı, Samanpazarı-Ankara, Turkey, 06100 (E-mail: kayicangir@hotmail.com).

J Thorac Cardiovasc Surg 2003;126:769-73

Copyright () 2003 by The American Association for Thoracic Surgery

$0022-5223 / 2003 \$ 30.00+0$

doi:10.1016/S0022-5223(03)00366-0
Conclusion: Transthoracic approach is a useful and a safe surgical management of both pulmonary and upper surface of hepatic hydatid cysts.

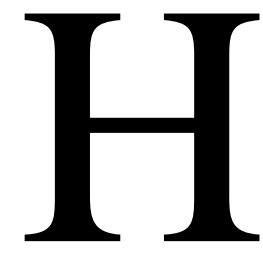

uman echinococcosis still remains a serious health problem for the Mediterranean countries. ${ }^{1-3}$ In Turkey, echinococcosis is an endemic disease, and annual incidence of hydatid disease is 4.9 cases per 100,000 inhabitants. ${ }^{4}$ In the Department of Thoracic Surgery, Ankara University School of Medicine, 70 to 80 patients per year are operated for hydatid disease.

In adults, pulmonary involvement, which follows hepatic infestation with a frequency of $50 \%$ to $70 \%$, has been observed in $18 \%$ to $35 \%$ of hydatidosis cases in some series. ${ }^{3,5,6}$ In children, hydatid disease is seen with a frequency of $64 \%$ in the lungs and $28 \%$ in the liver. ${ }^{7}$ Peleg and colleagues ${ }^{8}$ and Rami-Porta and 


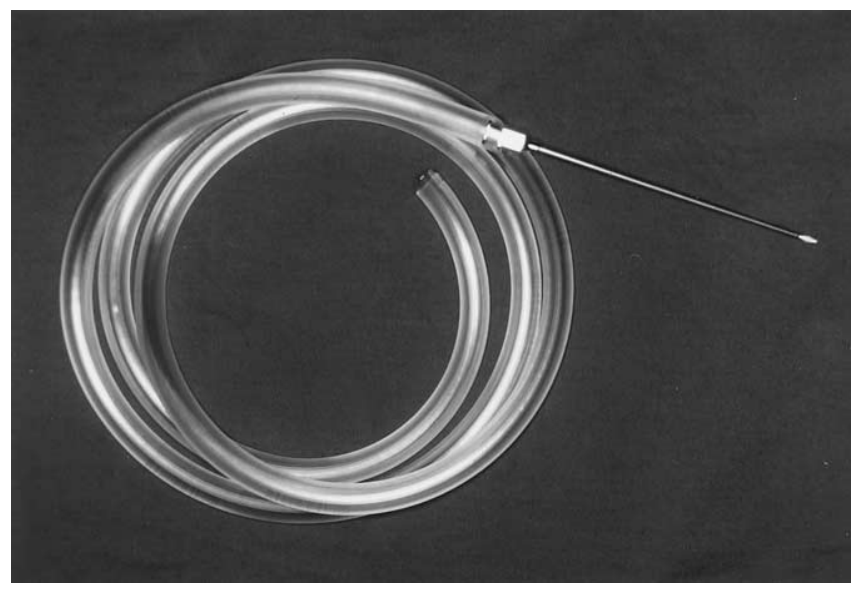

Figure 1. Needle aspirator for aspirating scolices and hydatid fluid.

coworkers ${ }^{9}$ reported that synchronous pulmonary and hepatic hydatid disease may occur in $4 \%$ to $25 \%$ of cases.

The aim of this study was to assess the efficacy of simultaneous surgical treatment of right lung and liver hydatid disease and to determine the safety of this approach and the results of follow-up.

\section{Patients and Methods}

Between 1990 and 2000, 773 patients with pulmonary hydatid cysts were operated on in the Department of Thoracic Surgery, Ankara University School of Medicine. Forty-eight of these patients had pulmonary and upper surface hepatic hydatid cysts, and these cysts were excised through right thoracotomy with a 1-staged procedure. All patients were evaluated with history and physical examination and blood tests including complete blood count and serum chemistries. Radiological examinations were investigated by chest radiography and/or thorax computed tomography (CT), and ultrasonography and/or CT scan of the upper part of the abdomen. The patients were evaluated according to sex, age, symptoms, clinical and radiographic findings, method of treatment, and prognosis.

\section{Surgical Technique}

We used right posterolateral thoracotomy. In cases with bilateral hydatid cysts, when it was not possible to reach the cysts via median sternotomy, the side with a larger cyst or with a greater number of cysts was treated first in bilateral uncomplicated hydatid cysts; second thoracotomy was performed 3 to 4 weeks after the first operation. In patients in whom an intact and a ruptured cyst was seen, the intact cyst was treated first. If a serious symptom like hemoptysis occurred, then the ruptured side was operated first. In patients with pulmonary and hepatic cysts, hepatic cysts were operated after the management of the lung cysts. However, we performed the simultaneous operations for hydatid cysts of the right lung and liver if a hepatic cyst was located in the dome of the liver.

Posterolateral thoracotomy was performed. The lung cysts were treated first and saline pads were packed beneath the lung, elevat-
TABLE 1. Occurrence of symptoms in 48 patients

\begin{tabular}{lcc}
\hline Symptoms & No. of patients & Percent \\
\hline Cough (alone) & 25 & 52.1 \\
Pain & 15 & 31.2 \\
Heamoptysis & 13 & 27.1 \\
Cough + sputum & 13 & 27.1 \\
Asymptomatic incidental findings & 2 & 4.2 \\
\hline
\end{tabular}

ing it to a fixed position, and also pleura was protected with these pads. Hydatid fluid and scolices were aspirated with needle aspirator (Figure 1). The 2 edges of the needle were held by 2 Allis clamps to prevent contamination of the pleural space by hydatid fluid during aspiration. After needle aspiration, pneumotomy was performed and membranes of the cysts were removed. The cyst cavity was irrigated with saline and the bronchial openings were sutured. In cases with infected cysts, one of the bronchial openings was left unsutured for the drainage of the infected fluid. The capitonnage was performed with fine sutures, and the opposing surface was approximated face-to-face in multiple, sutured rows to eliminate dead space. Coated polygalactin suture material was used in capitonnage. Cystotomy was performed when the cyst cavities were small. Wedge resection was performed for peripheral cysts when the surrounding pulmonary parenchyma was damaged.

After surgical treatment of pulmonary cysts, the right hemidiaphragma was incised radially over hepatic cysts, and then hepatic cysts were removed as pulmonary cysts. Hepatic hydatid cysts were treated by cystotomy with/without capitonnage and pericystectomy. The management of hepatic cysts was completed before suturing the diaphragm. A tube was positioned into the cystic cavity when biliary duct leakage was suspected. All cysts were examined microscopically to confirm the diagnosis.

Major complications were accepted as hemorrhage causing reexploration, pulmonary embolus, bronchopleural fistula, empyema, and chylothorax. Minor complications were wound infection, prolonged air leakage, and sputum retention. Operative mortality was defined as death from any cause during hospitalization for lung/hepatic surgery or within 30 days of operation. Follow-up information was obtained for all patients, either during periodic clinic visits or contact with the patients or their relatives. Per our clinic's protocol for hydatid disease, all patients were followed up with posteroanterior and lateral chest $\mathrm{x}$-ray films as follows: the first month after the operation, twice in the first 6 months, and then every 6 months.

\section{Results}

There were $33(68.8 \%)$ female patients and 15 (31.2\%) male patients with ages ranging from 4 to 58 years (mean: 30.48 \pm 14.9 years). Six patients (left lung $=2$, hepatic $=2$ ) were operated previously because of hydatid disease. Two patients $(4.2 \%)$ were asymptomatic and the cyst was discovered incidentally upon plain chest $\mathrm{x}$-ray for other causes. The remaining patients presented with 1 or more symptoms; the most frequent symptoms being cough, thoracic pain, hemoptysis, and expectoration of sputum (Table 1). The pulmonary cysts were diagnosed by plain chest $\mathrm{x}$-ray in 18 


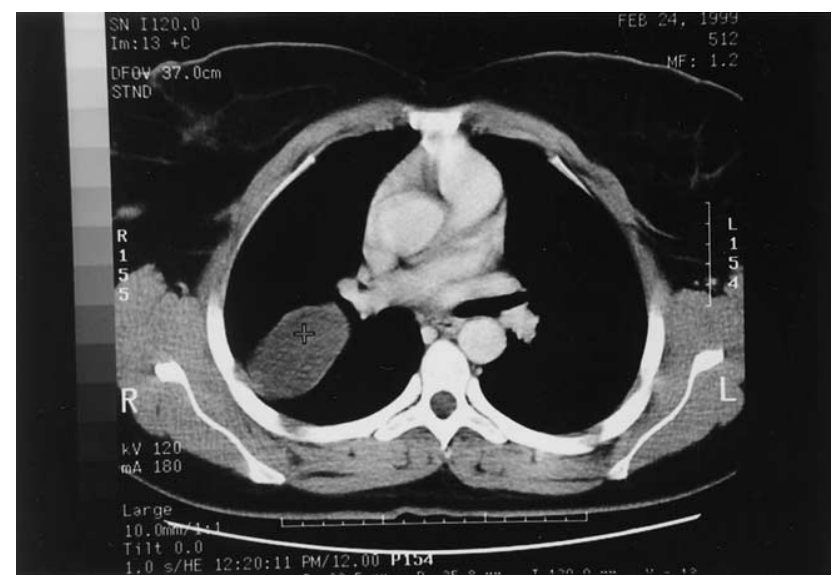

Figure 2. Preoperative CT scan of the chest showing hydatid cyst.

patients, and an additional thorax CT scan was performed in 30 patients who were operated after 1991 (Figure 2). The cysts were unilateral in 39 patients and bilateral in 9 patients. Radiographic examination of 48 patients showed 75 pulmonary cysts (Table 2). Ultrasonographic examination was performed in 18 cases and CT scan examination of the upper abdomen in 30 cases for diagnosis of hepatic cysts, and as a result 48 hepatic cysts were detected (Figure 3).

Eighteen cases (37.5\%) presented as a solitary lung cyst, while the remaining $30(62.5 \%)$ were found to have multiple cysts in 1 or both lungs.

In $38(79.1 \%)$ patients a simple pulmonary cyst was observed. These simple cysts were seen as round, homogeneous, well-defined densities. There were signs of cyst rupture in 10 patients (20.9\%). They consisted of the meniscus sign, an incarcerated membrane, the "water lily" sign and air-fluid levels. All the patients had intrabronchial perforation of the cyst.

In 48 patients, 57 posterolateral thoracotomies were performed. In cases with pulmonary cysts, cystotomy and capitonnage were performed in 32 patients, cystotomy was done in 15 patients, and only 2 patients underwent wedge resection because of the damaged surrounding pulmonary tissue.

Liver cysts were managed transdiaphragmatically after dealing with the lung cysts. Cystotomy and indwelling tube drainage were performed in 24 patients, cystotomy was used in 20 patients, marsupialization was done in 2 patients, and in the remaining patients, pericystectomy $(\mathrm{n}=1)$ and enucleation $(\mathrm{n}=1)$ were performed. We used no scoliocidal agent in our approach. Chest tubes were used in all cases.

There was no hospital mortality. Major postoperative complications were hemorrhage $(\mathrm{n}=1)$ and biliocutaneous fistula $(\mathrm{n}=1)$. Pulmonary recurrence after operation was seen in 1 patient with multiple cysts $(2.1 \%)$ and rethoracotomy was performed. Hepatic recurrence was seen in 3

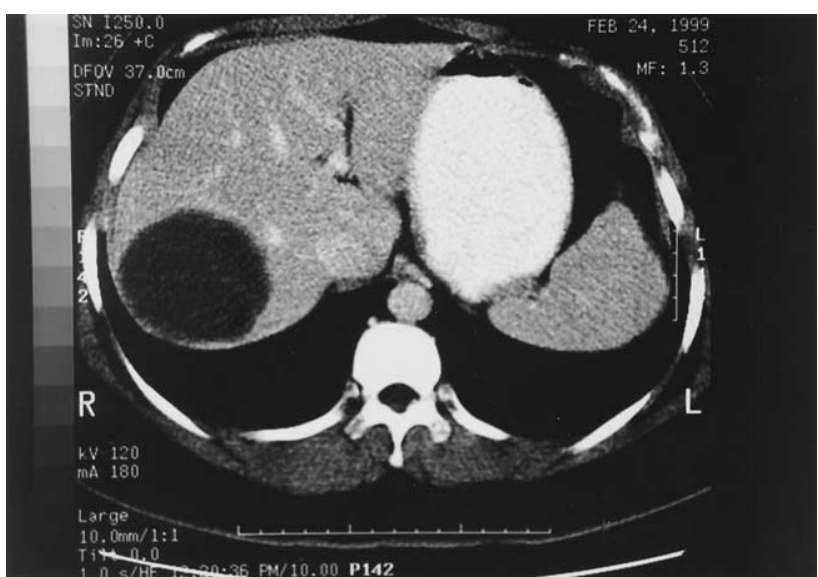

Figure 3. Upper abdominal CT scan of same patient with liver hydatid cyst.

\section{TABLE 2. Location of pulmonary cysts in $\mathbf{4 8}$ patients}

\begin{tabular}{lrr}
\hline & Right lung & Left lung \\
\hline Upper lobe & $24(39.3 \%)$ & $3(21.4 \%)$ \\
Middle lobe & $9(14.8 \%)$ & \\
Lower lobe & $28(45.9 \%)$ & $11(78.6 \%)$ \\
Total & $61(81.3 \%)$ & $14(18.7 \%)$
\end{tabular}

patients (6.2\%) and laparotomy was done in the Department of General Surgery.

\section{Discussion}

Hydatid cyst can be seen in almost every part of the body and it can involve multiorgans. Synchronous pulmonary and hepatic hydatid cysts may occur in $4 \%$ to $25 \%$ of cases. ${ }^{9}$ Diagnosis and surgical treatment of pulmonary and hepatic hydatid disease is very important in these patients.

In our series, CT scans of pulmonary cysts and CT scans and/or ultrasonography of the upper abdomen for hepatic cysts were used in preoperative diagnosis. The most important diagnostic tools in pulmonary hydatid cysts are plain $\mathrm{x}$-ray and CT scan. It is typical for an intact cyst to present as a round or oval homogenous density with sharp contours. ${ }^{10,11} \mathrm{CT}$ is also a successful method in the diagnosis of complicated hydatid cysts. CT scanning has come to the rescue of the clinician in elucidating the cystic nature of the lung mass with accurate localization for planning of surgical treatment. ${ }^{10,11}$ The preoperative diagnosis based on radiological findings was correct in all our cases. Immunological tests (ie, Casoni's skin test and Weinberg's complement test) were not used in this series because of their lower sensitivity and specificity compared with radiological examinations. ${ }^{5}$ Eosinophilia is a nonspecific finding that can be seen in many parasitic infections. As a result, we do not use or recommend these tests for diagnosis of pulmonary and hepatic hydatid diseases. 
The current treatment of pulmonary hydatid cyst is surgical. The objective of surgery is to maintain the maximum amount of viable lung while providing complete removal of all viable parasitic material. The most common surgical procedure is cystotomy and capitonnage in cases with intact cysts. ${ }^{5,12}$ Cystotomy with the pneumotomy line sutured was preferred in cases with infected and small cysts. ${ }^{5}$ In cases with infected cysts, there must be only 1 drainage bronchus for infected fluid because if all the bronchial openings are closed, lung abscess is inevitable. We saw no complication due to this method. However, we believe that the experience of the surgeon is an important factor for low operative morbidity in cases with hydatid disease. Large peripheral cysts should not be closed by capitonnage because this may restrict lung expansion. ${ }^{5}$ We agree that the attempt should be made to remove as little lung tissue as possible and that resection of pulmonary parenchyma is only indicated when the adjacent tissue is seriously damaged or when the atelectatic areas are presumably irrecoverable. We believe that resection should be avoided whenever possible. Pericyst is not parasitic and surrounding tissues can be atelectatic but often not infected. ${ }^{13}$

Resection of pulmonary hydatid cyst, such as lobectomy, in most instances has been reported in countries where hydatidosis is sporadic, even with rates of $20 \% .{ }^{13}$ We do not recommend any resection, in any age group, although giant cysts, multiple cysts, or lung abscess due to them exist. It must always be remembered that a patient may return to an endemic area and there is always a possibility of reinfestation.

We did not introduce any solution into the cavity, but we protected the operating field with saline pads. However, some authors recommend the use of scoliocidal agents by injecting them into the endocystic cavity to kill protoscoleces. ${ }^{8,14}$ We do not agree with them, because unfortunately this may cause undesirable complications and even death due to leaking of scoliocidal agents into ectocystic cavity where several bronchial openings lay. We used needle aspiration involving trocar suction and eliminated the risk of intraoperative contamination. Furthermore, protection of the operative field with saline pads, gentle manipulation of the cysts, and irrigation of the cavity with saline helped to prevent recurrence. After emptying the hydatid contents, saline pads were always changed. In our series, only in 1 patient was rethoracotomy performed for recurrent disease after 5 months and in 3 patients laparatomy was done.

We do not recommend albendazole in the preoperative period because when the parasite in the lung dies, the membranes are retained and the patient requires an operation for recurrent infection. ${ }^{8}$ For the same reason percutaneous aspiration is not suitable for the treatment of pulmonary hydatid cysts. We now routinely prescribe albendazole
$(10 \mathrm{mg} / \mathrm{kg} / \mathrm{d})$ only after all surgically accessible multiple intact cysts have been removed.

The overall morbidity and mortality rates after surgical treatment of the pulmonary hydatid disease are $1.4 \%$ to $19.1 \%$ and $0.6 \%$ to $4.2 \%$, respectively. ${ }^{2,15}$ These rates in cases with hepatic cysts are $6 \%$ to $47 \%$ and $0 \%$ to $3 \%$, respectively. ${ }^{16,17}$ However, the morbidity rate was $4.2 \%$ and there was no hospital mortality in our series. A 1-stage procedure is a successful approach with its low morbidity and reduced hospital stay and cost, as seen in our series. ${ }^{13,14,18}$ When the approach to hepatic cysts far away from diaphragma through the thorax is impractical, patients are referred to general surgery.

In conclusion, we recommend that pulmonary resection of hydatic disease should be avoided. Small or peripheric cystic cavities can be left open after closure of the bronchial openings. There must be only 1 drainage bronchus in cases with infected cysts. All patients with pulmonary hydatid cyst should be investigated for hepatic cyst, and ultrasonography and/or CT scan are useful methods for this investigation. If the cysts are accessible through the diaphragm, they can be operated at the right thoracotomy with low operative morbidity.

\section{References}

1. Aletras H, Symbas PN. Hydatid disease of the lung. In: Shields TW, LoCicero J III, Ponn RB, editors. General thoracic surgery. 5th ed. Philadelphia: Lippincott Williams and Wilkins; 2000. p. 1113-22.

2. Burgos R, Varela A, Castedo E, et al. Pulmonary hydatidosis: surgical treatment and follow-up of 240 cases. Eur J Cardiothorac Surg. 1999;16:628-35

3. Freixinet JL, Mestres CA, Cugat E, et al. Hepaticothoracic transdiaphragmatic echinococcosis. Ann Thorac Surg. 1988;45:426-9.

4. Health Statistics. Ankara, Turkey: Republic of Turkey Ministry of Health, Research Planning and Coordination Council; 2000. p. 54.

5. Yalav E, Ökten İ. Surgical treatment methods of pulmonary cysts. Ankara, Turkey: Ankara University Medical Faculty Publications; 1980 (in Turkish).

6. Ramos G, Orduna A, Garcia-Yuste M. Hydatid cyst of the lung: diagnosis and Treatment. World J Surg. 2001;25:46-57.

7. Tsakayiannis E, Pappis C, Moussatos G. Late results of the conservative surgical procedures in hydatid disease of the lung in children. Surgery. 1970;68:379-82.

8. Peleg H, Best LA, Gaitini D. Simultaneous operation for hydatid cysts of right lung and liver. J Thorac Cardiovasc Surg. 1985;90:783-7.

9. Rami-Porta R, Aisconde JG, Bravo-Bravo JL, Alix-Trueba A, SerranoMunoz F. Treatment of synchronous pulmonary and hepatic hydatid cysts. J Thorac Cardiovasc Surg. 1986;92:314-5.

10. Gouliamos AD, Kalovidouris A, Papailiou J, Vlahos L, Papavasiliou C. CT appearance of pulmonary hydatid disease. Chest. 1991;100:1578-81.

11. Koul PA, Koul AN, Wahid A, Mir FA. CT in pulmonary hydatid disease. Unusual appearances. Chest. 2000;118:1645-7.

12. Blanton R. Pulmonary echinococcosis. In: Mahmoud AAF, editor. Parasitic lung diseases, Vol 101. New York: Marcel Decker Inc; 1997. p. 171-89.

13. Athanassiadi K, Kalavronziotis G, Loutsidis A, Bellenis I, Exarchos N. Surgical treatment of echinococcosis by a transthoracic approach: a review of 85 cases. Eur J Cardiothorac Surg. 1998;14:134-40.

14. Dhaliwal RS, Kalkat MS. One-stage surgical procedure for bilateral lung and liver hydatid cysts. Ann Thorac Surg. 1997;64:338-41. 
15. Arıbaş OK, Kanat F, Türk E, Kalaycı MU. Comparison between pulmonary and hepatopulmonary hydatidosis. Eur J Cardiothorac Surg. 2002;21:489-96.

16. Yorgancı K, Sayek İ. Surgical treatment of hydatid cysts of the liver in the era of percutaneous treatment. Am J Surg. 2002;184:63-9.
17. Magistrelli P, Masetti R, Coppola R. Surgical treatment of disease of liver. Arch Surg. 1991;126:518-23.

18. Jakob H, Kohlhaüfl M, Hürter T, Steppling H, Oerlert H. Echinococcal disease of both lungs and liver: successful simultaneous resection. J Thorac Cardiovasc Surg. 1989;97:640-1.

\section{Authoritative}

The Journal of Thoracic and Cardiovascular Surgery is the most frequently cited thoracic/cardiovascular surgery journal in the Science Citation Index. An article in JTCVS is cited on average almost twice as often as those in the closest cardiothoracic journal. 